
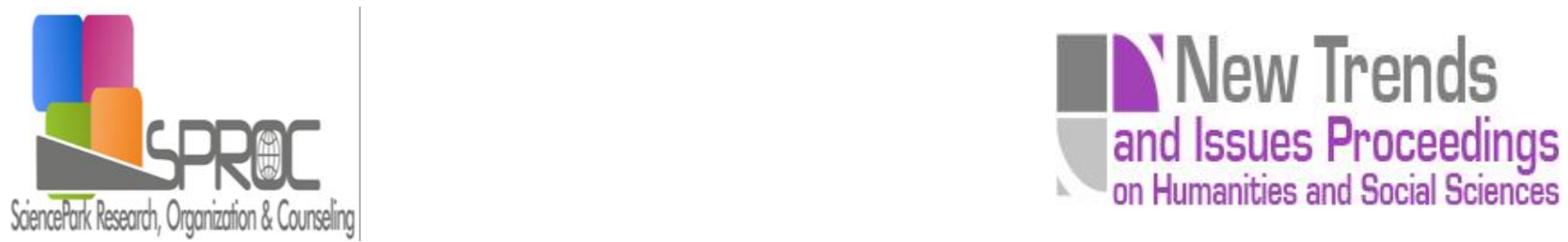

\title{
Practices that promote comprehensive school safety
}

Anna Diaz-Vicarioa *

Suggested Citation:

on Humanities and Social Sciences.

New Trends and Issues Proceedings

Abstract 
1. Introduction 


\section{Methods}

Table 1. Sample

$\begin{array}{lll}2 \text { public } & 2 \text { public } & 2 \text { public } \\ 1 \text { private } & 1 \text { private } & 1 \text { private }\end{array}$




\section{Findings}

(IES_03_PRIV-PROF_05, 105:105)

\subsection{Practices that promote physical safety}

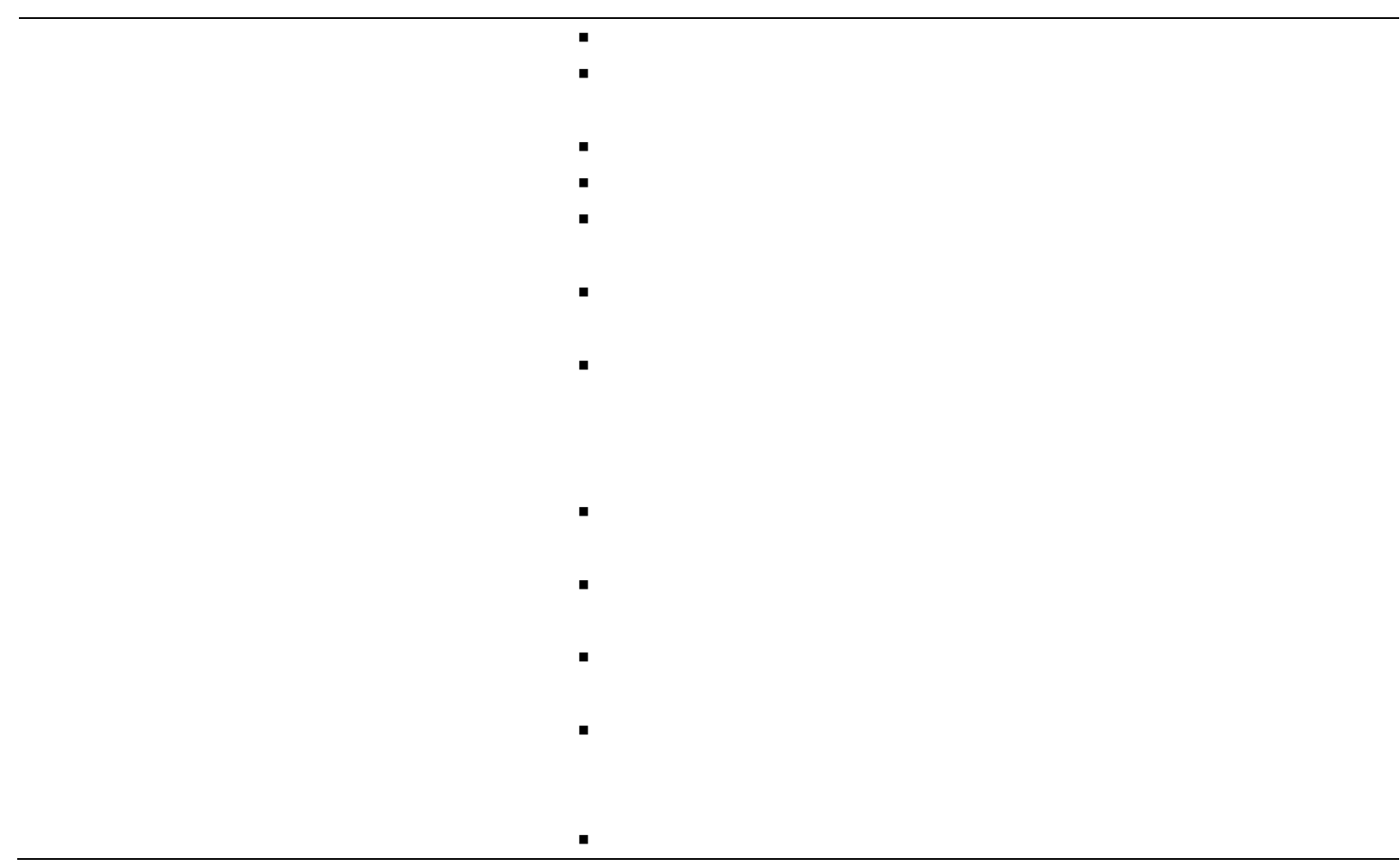


.

(SS_03_PRIV-PROF_06, 21:21)

(SS_02_PUB-OD_12). 


\subsection{Practices that promote emotional and social well-being}

(PS_02_PUB-FAM_04, 45:45)

(SS_02_PUB-PROF_11, 87:87)

(PS_01_PUB-PROF_15,

48:48) 
$\left.O D \_15,31: 31\right)$

\section{Discussion}

- 


\subsection{Conclusions}

\subsection{Recommendations}

\section{References}

Newsletter ENETOSH

Educar, 50

Making your school safe. Strategies to protect children and promote learning

Approach

Whole School

La organización escolar: contexto y texto de actuación.

Revista Española de Salud Pública, 75

Promoting safety - a component in health promotion in schools.

Forum: Qualitative Social Research,

El benestar a l'escola i en el professorat.L'estat de l'educació a Catalunya. Anuari 2011

Qualitative data analysis: An expanded sourcebook

Disaster prevention for schools. Guidance for Education Sector Decision-Maker

School safety and security. Lessons in danger

Safe and healthy schools: Practical prevention strategies

Generar escuelas promotoras de salud. Pautas para promover la salud en la escuela. Versión 2 del documento anterior denominado "Protocolos y directrices para las escuelas promotoras de salud 
Social Sciences, 5

Case study research: Design and methods 